\title{
Sperm-Impairing Escherichia coli, Alcohol and Male Infertility: An In Vivo Study
}

Prerna Bhardwaj, Kalpana Rana, Harpreet Vander, Praveen Bhandari and Vijay Prabha*

Department of Microbiology, Punjab University, Chandigarh-160014, India

\begin{abstract}
Purpose: Establishment of a male Balb/c mouse model to study the role of sperm immobilizing $E$. coli with or without alcohol on mouse reproductive potential.

Materials and Methods: The mice in the experimental groups were intraperitoneally administered with different doses $\left(10^{4}, 10^{6}\right.$ or $\left.10^{8} \mathrm{cfu}\right)$ of sperm immobilizing E. coli alone or in combination with alcohol and as control group alcohol alone or PBS for 10 consecutive days. The groups were evaluated for change in body weight, seminal parameters, bacterial load and histopathological changes.

Results: Weight gain was observed only in mice receiving PBS, whereas there was decrease in weight in all the groups except the group receiving $10^{4} \mathrm{cfu}$ where weight remained constant. No significant change in tissue somatic index was observed in any group. Reduced motility and viability was noticed in all groups except group receiving PBS. Decapitation was observed in groups instilled with $10^{4} \mathrm{cfu}$ and $10^{4} \mathrm{cfu}$ along with alcohol. Seminal parameters could not be evaluated due to non-specific aggregation of sperms in group administered with $10^{6}$ and $10^{8}$ cfu alone as well as with alcohol. Histopathological studies of testes showed very few mature spermatozoa and maturation arrest at later stage in all groups except PBS group.
\end{abstract}

Conclusion: Intraperitoneal inoculation with sperm immobilizing E. coli with or without alcohol consumption could lead to alteration of semen parameters, induction of decapitation in spermatozoa, thereby decreasing the reproductive potential of male mice.

Keywords: Escherichia coli; Male infertility; Immobilization; Decapitation; Sperms

\section{Introduction}

'Infertility is the inability of a sexually active, non-contracepting couple to achieve pregnancy in one year' [1]. Infertility being a multifarious condition, requiring multidisciplinary involvement, is caused by a variety of factors [2]. It is estimated that approximately $15 \%$ of couples worldwide suffer from infertility [3]. Male and female factors are equally responsible for infertility (30-40\%) and the remaining $10 \%$ is ascribed to idiopathic reasons [4]. The etiology of about $55 \%$ of infertility due to male factor is not known, however, bacterial infection may be the underlying causes in such cases [5]. Various factors that may lead to decrease of reproductive potential of males may include genetic or acquired conditions viz. urogenital abnormalities, varicocele, genetic diseases, endocrine disturbances, testicular failure, immunologic problems, cancer, systemic infections and genital tract, altered daily routine and exposure to gonadotoxic or ecological agents [6]. Amongst these, acute and chronic urogenital tract infections (UTI) play a prominent and unnoticed role [6]. Microbial agents affect fertility by causing obstruction of male reproductive system, sperm cell function impairment, testicular damage, epididymitis, and orchitis [7]. In vitro studies indicate that sperm motility is obstructed by different genera of bacteria like Escherichia coli, Ureaplasma urealyticum, Mycoplasma hominis and Staphylococcus aureus [8]. E. coli and Enterococci are the main microorganisms with the most detrimental influence on sperm motility and morphology [9]. E. coli is the most frequently involved in nonsexually transmitted epididymo-orchitis and also the prevelant in $65-80 \%$ of total cases of acute or chronic prostatitis [10]. Along with urogenital infections, an unhealthy lifestyle is also an important factor contributing to male infertility. Recent citations have put forward the idea that by implementing certain negative lifestyle like tobacco chewing, alcohol addiction, caffeine and use of illicit drugs, one is compromising with his reproductive health, consequently declining the human semen quality and productiveness [11]. Amongst these, alcohol consumption has shown deleterious effects at all levels of the male reproductive system by interfering with the function of each of components, thereby causing impotence, infertility, and reduced male secondary sexual characteristics. It has also been linked to the production of abnormal sperm cells with deformed heads and tails [12]. Available data do not conclusively demonstrate that alcohol uptake and E. coli decrease male fertility. However, with much debate for its impact on various semen parameters, it is regarded as a fertility risk factor. As indicated by various in vitro studies, attachment of E. coli and M. hominis to human spermatozoa has led to various morphological defects and thereby, a decrease in the fertilization potential of the spermatozoa [13]. However, there in vivo potential to cause infertility is yet to be annotated. In an earlier work in our laboratory we have isolated an E. coli strain which showed sperm immobilization in vitro, but whether it also has the potential to cause immobilization or any other degenerative effect on sperms in vivo was the subject of the present study. Therefore, we established a male Balb/c mice model to study the role of this E. coli strain with/without alcohol doses on mouse reproductive potential.

*Corresponding author: Vijay Prabha, Department of Microbiology, Panjab University, Chandigarh-160014, India, Tel: 91-9417065675; E-mail: satishvijay11@yahoo.com

Received June 03, 2015; Accepted June 06, 2015; Published June 09, 2015

Citation: Bhardwaj P, Rana K, Vander H, Bhandari P, Prabha V (2015) SpermImpairing Escherichia coli, Alcohol and Male Infertility: An In Vivo Study. J Med Microb Diagn 4: 195. doi:10.4172/21610703.1000195

Copyright: (c) 2015 Bhardwaj $P$, et al. This is an open-access article distributed under the terms of the Creative Commons Attribution License, which permits unrestricted use, distribution, and reproduction in any medium, provided the original author and source are credited. 


\section{Material and Methods}

\section{Animals}

Sexually mature 5-6 weeks old male $(25 \pm 2$ g) Balb/c mice were used in the present study. The animals were housed in polypropylene cages in the animal room of the Department of Microbiology, Punjab University, and Chandigarh, India. The animals were maintained in laboratory conditions (12:12, dark:light cycle) and fed with standard pellet diet and water ad libitum. All the experiments were approved by Institutional Animal Ethics Committee, Punjab University vide letter no. IAEC/504 dated 02.04.2014 and were completed in agreement with the guidelines of the Committee for the Purpose of Control and Supervision of Experiments on Animals (CPCSEA).

\section{Microorganism}

The Escherichia coli isolate showing maximum sperm immobilizing activity in vitro used in the current work was isolated from semen samples of males undergoing semen examination at Government Multi Speciality Hospital (GMSH), Sector 16, Chandigarh and special infertility clinic at Department of Urology, Post Graduate Institute of Medical Education and Research (PGIMER), Chandigarh, India.

\section{Effect of Multiple Doses of Sperm Immobilizing $E$. coli on Sperm Parameters in Male Mouse Model}

\section{Preparation of inoculum}

The sperm immobilizing E. coli strain was cultivated in BHI broth, incubated under shaking conditions $(150 \mathrm{rpm})$ for $24 \mathrm{~h}$ at $37^{\circ} \mathrm{C}$ and centrifuged at $10,000 \mathrm{~g}$ for $20 \mathrm{~min}$. The pellet so obtained was washed twice with PBS (50 mM, pH 7.2). The cells were resuspended in the same buffer so as to get $10^{4}, 10^{6}$, and $10^{8} \mathrm{cfu} / 20 \mu \mathrm{l}$.

\section{Intraperitoneal inoculation}

Mice were divided into 8 groups ( 5 mice in each) and administered intraperitoneally with $10^{4}, 10^{6}$ or $10^{8} \mathrm{cfu}$ of sperm immobilizing $E$. coli per mouse in $20 \mu \mathrm{l}$ PBS for 10 consecutive days without under any anesthesia. In parallel 15 mice with 5 mice in each group were inoculated intraperitoneally with $10^{4}, 10^{6}$, and $10^{8} \mathrm{cfu} / 20 \mu \mathrm{l}$ of sperm immobilizing $E$. coli along with oral administration with $200 \mu \mathrm{l}$ of $20 \%$ (W/V) of alcohol. As control, 5 mice were inoculated intraperitoneally with $20 \mu \mathrm{l}$ of PBS and one group was orally fed with $200 \mu \mathrm{l}$ of $20 \%$ (W/V) of alcohol alone respectively.

\section{Body weight and organ weight}

Initial body weight of mice from each group was taken on the $1^{\text {st }}$ day of experiment and final weight was on the last day of experiment. On $12^{\text {th }}$ day, mice from each group were sacrificed by cervical dislocation and the reproductive organs (viz. testes, cauda) were removed aseptically. The organs were then freed from adherent tissues and blood, grossly examined and weighed. The Tissue Somatic Index (percent organ weight in relation to body weight) was evaluated.

\section{Evaluation of Seminal Parameters}

\section{Sperm count}

Mice from each group were sacrificed by cervical dislocation on day 12 and were dissected. The vas deferens was pulled out and placed in freshly prepared RPMI medium $(1 \mathrm{ml})$ respectively. Gentle agitation and teasing was done to enable the spermatozoa to swim out into the freshly prepared RPMI in a glass plate. A fixed volume of $10 \mu \mathrm{l}$ of the sample was placed on a glass slide and examined at 400X magnification. The four to six fields were scanned and mean number of spermatozoa in several fields was multiplied by $10^{6}$.

\section{Motility}

Motility of the sperms extracted from the sacrificed mice was determined by the method of Emmens [14].

\section{Viability test}

In order to estimate the percentage of viable sperms, an equal volume of mouse spermatozoa was mixed with $0.5 \%$ eosin on a microscopic slide and examined under the light microscope at 400X.

\section{Bacterial count determination}

Testes and cauda were homogenised manually in PBS $(50 \mathrm{mM}$, $\mathrm{pH}$ 7.2) to form a uniform homogenate. $100 \mu$ l of serially diluted homogenate was plated on BHI agar plates and incubated overnight at $37^{\circ} \mathrm{C}$. The $\mathrm{cfu} / \mathrm{mice} / \mathrm{g}$ of tissue was calculated.

\section{Recovery of microorganisms}

$100 \mu \mathrm{l}$ of tissue homogenates as prepared above were streaked on selective media viz. MacConkey, Eosin Methylene Blue agar and Mannitol Salt Agar to recover the microorganisms present in the reproductive organs viz., testes and cauda after 10 days of inoculation with sperm immobilizing $E$. coli with/without alcohol.

\section{Histopathological Studies}

Histological analyses of the reproductive organs of mice from each group were carried out on day 12 . The reproductive organs (testes and cauda) were harvested, fixed in $10 \%$ formaldehyde for $24 \mathrm{~h}$ and then embedded in paraffin according to standard histological methods. Serial paraffin sections of $4 \mathrm{~mm}$ were stained with hematoxylin-eosin and observed at X400 for significant change in reproductive organs.

\section{Results}

Impact of intraperitoneal inoculation of sperm immobilizing E. coli alone and in combination with alcohol on sperm parameters. Evaluation of impact of sperm immobilizing E. coli on body weight, seminal parameters, bacterial load and histological changes was determined in each group.

\section{Weight profile}

Weight profile showed that the control group receiving PBS showed gain in weight, whereas decrease in weight $(2 \mathrm{~g})$ was seen in control group receiving alcohol. In case of group receiving $10^{4} \mathrm{cfu}$ alone weight remained constant while when alcohol was given along, there was decrease of $2 \mathrm{~g}$ in body weight. In the remaining groups, administered with $10^{6}$ and $10^{8} \mathrm{cfu}$ alone and in combination with alcohol decrease of $4 \mathrm{~g}$ was observed in weight. There was no significant change in weight profile of all the test groups when compared with control group receiving PBS (Figure 1).

\section{Tissue somatic indices (TSI \%)}

There were no significant changes in TSI of groups receiving different doses of sperm immobilizing E. coli alone and in combination with alcohol as compared to control.

\section{Evaluation of seminal parameters}

On day 12, post treatment, all the animals belonging to each group were sacrificed and dissected for evaluation of seminal parameters 


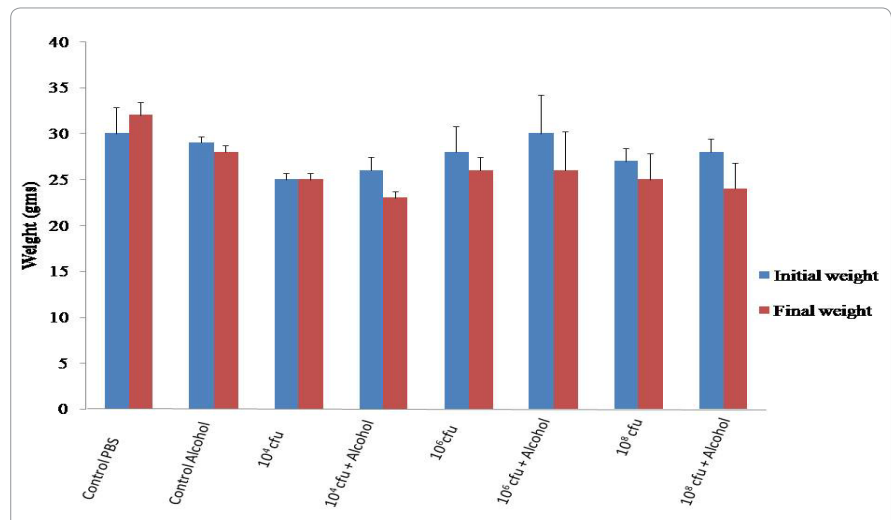

Figure 1: Body weights of mice after 10 days of treatment with sperm immobilizing $E$. coli alone and in combination with alcohol. Values represent mean $\pm S D$.

viz. sperm count, motility, viability and morphology. The results showed that sperm count in control group receiving PBS was $20 \mathrm{x}$ $10^{6} / \mathrm{ml}$, percentage motility and viability was found to be 50 and 60 respectively. On the other hand control group receiving alcohol alone showed sperm count of $15 \times 10^{6} / \mathrm{ml}$ and motility and viability was 20 and $30 \%$ respectively. When $10^{4} \mathrm{cfu}$ of sperm immobilizing $E$. coli alone or in combination with alcohol was infused, an alteration of seminal parameters was seen. The motility and viability of group administered with $10^{4} \mathrm{cfu}$ was reduced to $30 \%$ and $35 \%$ respectively and further declined to 10 and $20 \%$ along with alcohol. Interestingly, in addition, $25 \%$ decapitation of mouse spermatozoa was also observed when administered with $10^{4} \mathrm{cfu}$ alone. This effect was more pronounced in group receiving alcohol in combination with sperm immobilizing $E$. coli where $60 \%$ decapitation was seen.

However as a result of nonspecific aggregation of spermatozoa due to presence of pus cells, in case of mice receiving $10^{6}, 10^{8} \mathrm{cfu}$ alone as well as in combination with alcohol, none of the seminal parameters could be evaluated (Table 1 and Figure 2).

\section{Viable bacterial load determination}

The bacterial load from mice sacrificed on day 12 was determined. The number of bacteria recovered from both testes and cauda were generally similar. Moreover, in all the mice not more than 10 fold difference in the number of cfu was observed as compared to control.

\section{Recovery of bacteria}

The E. coli was recoverd from homogenates of testes and cauda of mice administered with $10^{8} \mathrm{cfu}$ sperm immobilizing $E$. coli alone and with alcohol respectively. The recovered E. coli showed sperm immobilization which was checked in vitro.

\section{Histopathological examination}

Histopathological examination revealed that the testes of control group receiving PBS was normal showing clusters of spermatozoa in the centre surrounded by layers of germinal cells. The control group receiving alcohol showed late maturation arrest. In case of $10^{4}, 10^{6}, 10^{8}$ cfu of sperm immobilizing E. coli alone or in combination with alcohol, testes showed very few mature spermatozoa and maturation arrest at late stage. The cauda was normal in all the groups and was comparable to control (Figures 3 and 4).

\section{Discussion}

E. coli is one of the most prevalent bacteria isolated from the semen samples of males attending infertility clinic [12]. To the best of our knowledge, no data exist in literature that suggests apparent relationship of $E$. coli with male infertility. Despite the fact that a lot of research has been done on the in vitro effects of bacteria on sperm, no in vivo effects has been demonstrated. In addition to genital tract infections, lifestyle choices like drinking and smoking can also have atrocious effect on male fertility. The effect of alcohol on sperm morphology has not been studied extensively, although there are suggestions that alcohol may affect male fertility [15]. In this study Male Balb/c mice were inoculated intraperitoneally with different doses of sperm immobilizing $E$. coli with/without alcohol while control group received PBS/ alcohol $(20 \mu \mathrm{l})$ for 10 consecutive days. Mice were sacrificed on $12^{\text {th }}$ day and various parameters were evaluated. Weight profile studies showed weight gain in mice receiving PBS in contrast to mice receiving alcohol and mice administered with $10^{6}$ and $10^{8} \mathrm{cfu}$ of sperm immobilizing E. coli alone or in combination with alcohol where decrease in weight was observed. However, constant weight gain was observed in mice administered with $10^{4} \mathrm{cfu}$ of sperm immobilizing E. coli. Zhu et al. [16] while studying the role of macrophage in bacterial infections has also reported loss in weight of mice upon infection with bacteria [16]. Lieber while exploring the relationships between a person's alcohol consumption, its nutritional status, and the associated risk of alcoholic liver disease found that although the participants received the similar amount of calories, those in alcohol group showed a decrease in body weight compared with those in the control group [17]. In all groups, there was no significant change observed in tissue somatic index. These results are in concordance with Kaur et al. [18] where no significant changes in TSI of all the reproductive and non-reproductive organs were observed in female mice receiving intravaginal sperm agglutinating S. aureus and E. coli as compared to control $[18,19]$. Decapitation was observed with $10^{4} \mathrm{cfu}$ alone and with alcohol while reduced motility and viability was noticed with alcohol as compared to control group. A study by Grewal et al. [20] showed that the culture supernatants of Bacillus sp. and Pseudomonas sp. not only decreased the motility of spermatozoa but also decapitated a few spermatozoa [20]. Structural and functional integrity is compromised as a consequence of acute uropathogenic $E$. coli associated epididymitis [21]. In addition, alcohol consumption was associated with increased numbers of morphologically abnormal sperm [22]. Donnelly et al. [23] found that when alcohol was added to sperm directly, at concentrations equal to those in serum after drinking, deteriorating effects were observed in both sperm motility and morphology [23]. Due to nonspecific aggregation of spermatozoa, seminal parameters could not be evaluated in case of mice administered with $10^{6}$ and $10^{8} \mathrm{cfu}$ alone as well as with alcohol. Findings by Moretti et al. [13] showed that the simple presence of bacteria might alter the quality of spermatozoa [13]. The average sperm concentration in the individuals positive for bacteria was significantly lower than that observed in controls. Animals infected with pathogenic E. coli and P. aeruginosa had a low sperm count while the control group showed an improved count [24]. Khan et al. [25] while studying the relationship between semen quality, pyospermia, and microbiology showed that pyospermia is associated either with reduced sperm motility or altered normal morphology [25]. It has also been reported that a significant positive correlation exists between pyospermia and compromised sperm morphology, that includes tail defects, damage to acrosome, and SDI scores [26]. Recovery of E. coli from testes and cauda revealed only $1 \log$ cfu increase at the most from all groups $\left(10^{4}, 10^{6}, 10^{8} \mathrm{cfu}\right.$ alone as well as with alcohol). Histopathological studies of testes showed very few mature spermatozoa and of maturation arrest at later stage in all groups except PBS group. These results are in accordance to the $20 \%$ arrested sperm 
Citation: Bhardwaj P, Rana K, Vander H, Bhandari P, Prabha V (2015) Sperm-Impairing Escherichia coli, Alcohol and Male Infertility: An In Vivo Study. J Med Microb Diagn 4: 195. doi:10.4172/21610703.1000195

Page 4 of 5

\begin{tabular}{|c|c|c|c|c|c|c|c|c|}
\hline Treatment dose. & Control & $10^{4} \mathrm{cfu}$ & $10^{6} \mathrm{cfu}$ & $10^{8} \mathrm{cfu}$ & Alcohol & $10^{4} \mathrm{cfu}+$ alcohol & $10^{6} \mathrm{cfu}+$ alcohol & $10^{8} \mathrm{cfu}+$ alcohol \\
\hline No. of pus cells & - & - & 3/field, & Clump of pus cells & - & - & - & $\begin{array}{l}\text { Clumps of pus } \\
\text { cells }\end{array}$ \\
\hline $\begin{array}{l}\text { Sperm count }\left(x 10^{6}\right. \\
/ \mathrm{ml})\end{array}$ & $20 \pm 1.4$ & $20 \pm 7.0$ & $\begin{array}{l}\text { Nonspecific } \\
\text { aggregation of } \\
\text { sperms }\end{array}$ & $\begin{array}{l}\text { Nonspecific } \\
\text { aggregation of } \\
\text { sperms }\end{array}$ & $15 \pm 2.8$ & $20 \pm 5.6$ & $\begin{array}{l}\text { Nonspecific } \\
\text { aggregation of } \\
\text { sperms }\end{array}$ & $\begin{array}{l}\text { Nonspecific } \\
\text { aggregation of } \\
\text { sperms }\end{array}$ \\
\hline Motility \% & $50 \pm 2.8$ & $30 \pm 4.2^{a}$ & N.D & N.D & $20 \pm 0^{a}$ & $10 \pm 4.3^{a}$ & N.D & N. D \\
\hline Viability \% & $60 \pm 5.6$ & $35 \pm 1.4$ & N.D & N.D & $30 \pm 4.2$ & $20 \pm 5.7$ & N.D & N.D \\
\hline Morphology & Normal & $\begin{array}{l}\text { Decapitation } \\
25 \%\end{array}$ & Normal & Normal & Normal & Decapitation $60 \%$ & N.D & N.D \\
\hline
\end{tabular}

Data represents mean \pm SD value. ${ }^{a}$ indicates $p$ value $<0.05$

Table 1: Seminal parameters of male mice after 10 days of treatment with sperm immobilizing $E$. coli alone and along with alcohol.

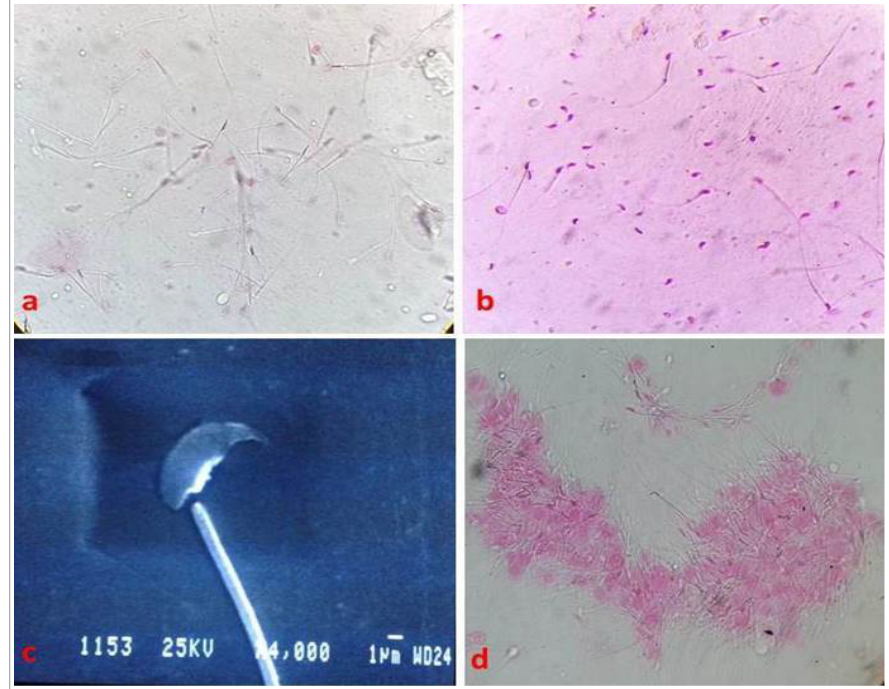

Figure 2: (a) Light micrograph of spermatozoa of control group receiving PBS (b) light micrograph of decapitated spermatozoa from mouse administered with $10^{4} \mathrm{cfu}$ of sperm immobilizing $E$. coli (c) Electron micrograph of spermatozoa showing decapitation (d) Representative light micrograph of nonspecific aggregation of spermatozoa due to pus cells in mouse administered with $10^{8} \mathrm{cfu}$ of sperm immobilizing $E$. coli along with alcohol.
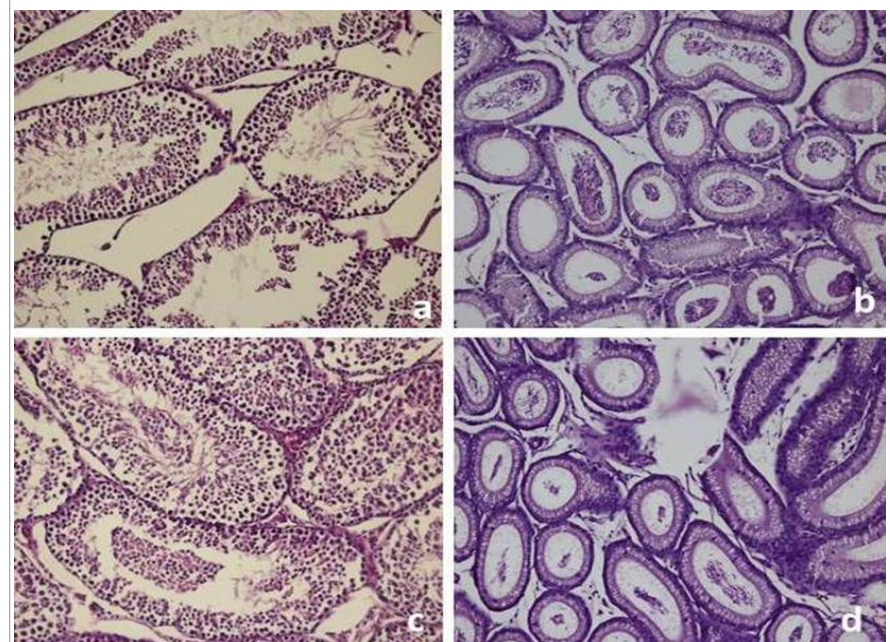

Figure 3: Histopathological examination of reproductive organs testes and cauda $(\mathrm{a}, \mathrm{b})$ control group receiving PBS $(\mathrm{c}, \mathrm{d})$ group receiving alcohol alone.
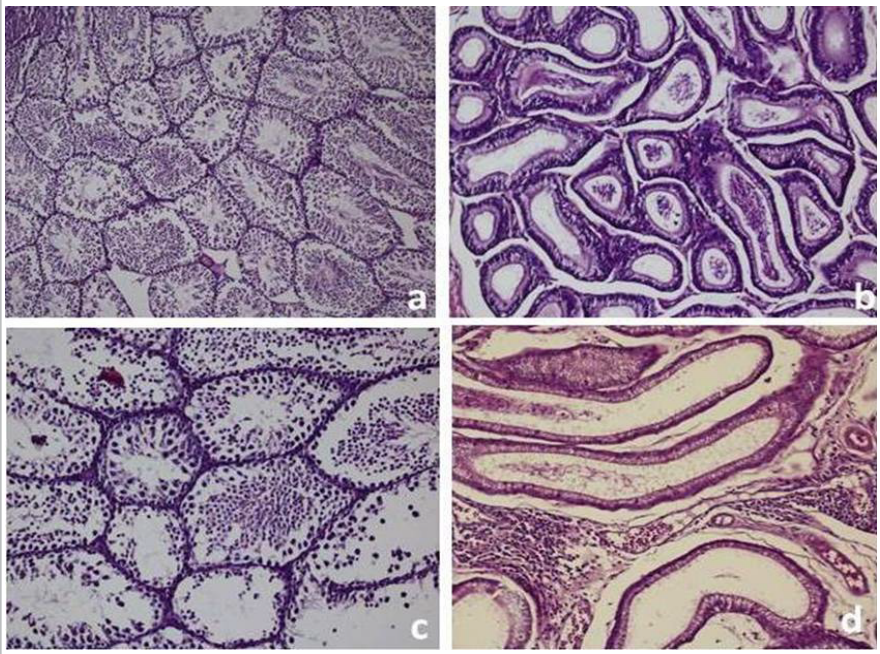

Figure 4: Histopathological examination of reproductive organs testes and cauda $(a, b)$ representative photomicrograph of groups administered with sperm immobilizing $E$. coli alone (c, d) representative photomicrograph of groups administered with sperm immobilizing $E$. coli in combination with alcohol respectively.

development, $40 \%$ reduced sperm counts, $45 \%$ abnormal sperm and $50 \%$ altered sperm motility on alcohol consumption in men studied, reported by Villalta et al. [27].

\section{Conclusion}

Our data showed that intraperitoneal inoculation with spermimpairing E. coli with or without alcohol consumption could lead to alteration of semen parameters, induction of decapitation in spermatozoa, and decrease of the reproductive potential of male mice. These significant modifications suggest that alcohol may aggravate alteration of seminal parameters induced by $E$. coli indicating synergic or additive effect of both on reproductive potential.

\section{Acknowledgement}

This work was supported by financial support from Department of Science and Technology, New Delhi, India.

\section{References}

1. World Health Organization Global Strategy for the prevention and Control of Sexually Transmitted Infections: Cambridge, United Kingdom: Cambridge university Press 2006.

2. Agboola A (2004) Infertility and Subinfertility. In: Akin A (ed.) Textbook of Obstetrics and Gynaecology, Ibadan Heinman Educational Books 1: 174-176. 
Citation: Bhardwaj P, Rana K, Vander H, Bhandari P, Prabha V (2015) Sperm-Impairing Escherichia coli, Alcohol and Male Infertility: An In Vivo Study. J Med Microb Diagn 4: 195. doi:10.4172/21610703.1000195

Page 5 of 5

3. Hellani A, Al-Hassan S, labal MA (2006) Y chromosome microdeletions in infertile men with idiopathic oligo- or azoospermia. J Exp Clin Assist Reprod 3: 1 .

4. Ouzounova-Raykova V, Ouzounoval, Mitov I (2009) Chlamydia trachomatis infection as a problem among male partners of infertile couples. Andrologia 41: 14.

5. Samplaski MK, Domes T, Jarvi KA (2014) Chlamydial Infection and its role in male infertility. Adv Androl 11.

6. Dohle GR, Diemer T, Giwercman A (2010) Guidelines on male infertility. EAU guidelines, edition presented at the 25th EAU Annual Congress, Barcelona..

7. Dieterle S (2008) Urogenital infections in reproductive medicine. Andrologia 40: 117.

8. Moretti E, Capitani S, Figura N, Pammolli A, Federico MG, et al. (2009) The presence of bacteria species in semen and sperm quality. J Assist Reprod Genet 26: 47.

9. Golshani M, Taheri S, Eslami G, Suleimani Rahbar AA, Fallah F, et al. (2006) Genital tract infection in asymptomatic infertile men and its effect on semen quality. Iran J Public Health 35: 81.

10. Pellati D, Mylonakis I, Bertoloni G, Fiore C, Andrisani A, et al. (2008) Genital tract infections and infertility. Eur J Obstet Gynecol Reprod Biol 140: 3

11. Ten J, Mendiola J, Alberto M, José M, Moreno S, et al. (2008) Occupational and Lifestyle Exposures on Male Infertility- A Mini Review. Torsj 1: 16.

12. Diemer T, Huwe $P$, Ludwig M, Schroeder-Printzen I, Michelmann HW, et al (2003) Influence of autogenous leucocytes and Escherichia coli on sperm motility parameters in vitro. Andrologia 35: 100

13. Moretti E, Capitani S, Figura N, Pammolli A, Federico MG, et al. (2009) The presence of bacteria species in semen and sperm quality. J Assist Reprod Genet 26: 47.

14. Emmens CW (1947) The motility and viability of rabbit spermatozoa at different hydrogen ion concentrations. J Physiol 106: 471

15. Marinelli D, Gaspari L, Pedotti P (2004) Mini-review of studies on the effect of smoking and drinking habits on semen parameters. Int J Hyg Environ Heal 207: 185.
16. Zhu X, Westcott MM, Xin Bi, Gowdy KM, Seo J, et al. (2012) Myeloid CellSpecific ABCA1 Deletion Protects Mice from Bacterial Infection. Circ Res 111 1398.

17. Lieber CS (2003) Relationships between Nutrition, Alcohol Use, and Liver Disease. Alcohol Res Health 27: 220.

18. Kaur S, Prabha V, Kaur K (2011) Safety studies of sperm agglutinating factor produced by Staphylococcus aureus as a vaginal contraceptive: in vivo studies. Gynecol Endocrinol 27: 956.

19. Kaur K, Prabha V (2014) Spermagglutinating Escherichia coli and its role in infertility: In vivo study. Microb Pathog 69: 33.

20. Grewal RK, Prabha V, Malhotra SK (2007) Decapitation of spermatozoa by endocervical isolates from cases of unexplained infertility. J Obstet Gynaecol India 57: 426.

21. Lang T, Dechant M, Sanchez V (2013) Structural and functional integrity of spermatozoa is compromised as a consequence of acute uropathogenic E. coli -associated epididymitis. Biol Reprod 19: 89

22. Joo KJ, Kwon YW, Myung SC (2012) The Effects of Smoking and Alcohol Intake on Sperm Quality: Light and Transmission Electron Microscopy Findings. J Int Med Res 40: 2327.

23. Donnelly GP, McClure N, Kennedy MS (1999) Direct effect of alcohol on the motility and morphology of human spermatozoa. Andrologia 31: 43.

24. Majolagbe ON, Oloke JK, Adebayo EA (2013) Study on the Antibacterial Activity of Exopolysaccharides of Lentinus subnudus Using Swiss Albino Rats as Animal Model. AEJSR 8: 47.

25. Khan MS, Mohammad SH, Deepa F, Tahir F (2012) Association between Pus Cells and Semen Parameters in Infertile Pakistani Males. Sultan Qaboos Univ Med J 12: 479 .

26. Aziz N, Buchan I, Taylor C, Kingsland CR, Lewis-Jones I, et al. (1996) The sperm deformity index: A reliable predictor of the outcome of oocyte fertilization in vitro. Fertil Steril 66: 1000

27. Villata J, Ballesca JL, Nicolas JM, Martínez de Osaba MJ, Antúnez E, et al. (1997) Testicular function in asymptomatic chronic alcoholics: Relation to ethanol intake. Alcoholism: Alcohol Clin Exp Res 21: 128. 